\title{
23
}

\section{Modeling Siphon Weirs within EXTRAN}

\author{
William James and Brett C. Young
}

This chapter presents the background for new code for simulating self-priming siphon-weirs within the Extended Transport (EXTRAN) module of the Stormwater Management Model, Version 4 (SWMM4). The new code handles unsteady flow conditions occurring in real sewer systems, and has been verified under a range of flow conditions, and found to produce good results for the conditions examined.

\subsection{Introduction}

Siphon-weirs are most often used in dam spillways - in fact they are more usually termed siphon spillways. These structures provide an effective means of flood relief and have a high overflow capacity for a relatively small structure, making them suitable for use when available space is limited. They may also be effectively used in combined sewer systems to provide relief during periods of high storm flow. Siphon-weirs are usually self-priming and allow for large overflows in a short period of time, thus preventing high water levels, surcharge, and possible flooding in low lying areas. While the water levels over a fixed weir may fluctuate according to the discharge over the weir, the siphonweir design enables a fairly constant upstream water level to be maintained, regardless of the discharge (Schoklitsch, 1937; Vancouver City Engineering Department, 1985).

As the water level in the interceptor, $Y_{l}$, (notation used is given in Figure 23.1) rises above the crest of the siphon-weir, $Y_{c}$, water begins to flow over the spillway crest in a thin sheet, in the same manner as it would over a side weir structure. The crest and entrance designs usually consist of gradual curves

James, W. and B.C. Young. 2001. "Modeling Siphon Weirs within EXTRAN." Journal of Water Management Modeling R207-23. doi: 10.14796/JWMM.R207-23.

(C) CHI 2001 www.chijournal.org ISSN: 2292-6062 (Formerly in Models and applications to Urban Water Systems. ISBN: 0-9683681-4-X) 


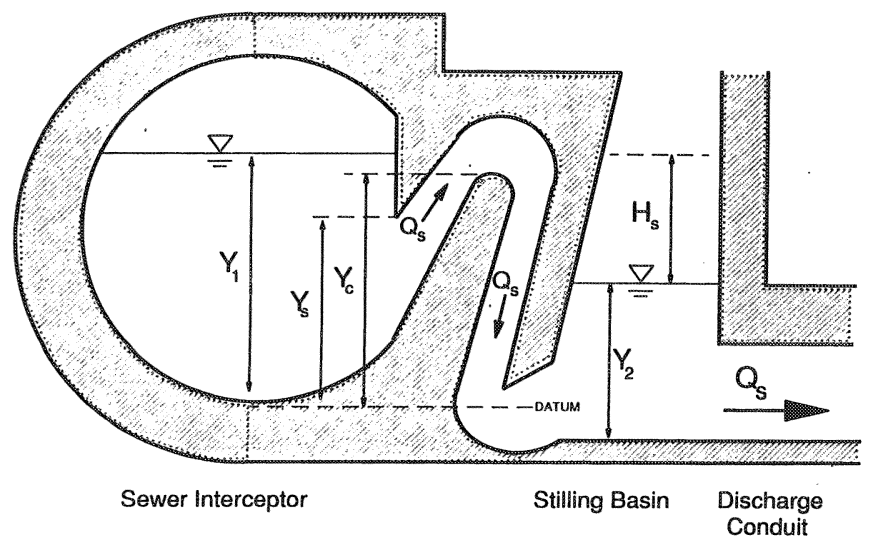

Figure 23.1 Siphon weir notation.

which reduce energy losses and improve the efficiency of the siphon. When the overflowing water strikes the stationary tailwater in the stilling basin, air is forcibly extracted from the siphon, until a vacuum is created and the siphon primes (Schoklitsch, 1937). The stilling basin should be designed such that the end of the siphon is submerged, in order to facilitate the siphon priming. This priming action is very rapid and allows the full capacity of the siphon to be realized with very little increase in the upstream head.

Air valves may be used to introduce air into the structure and thus prevent the siphon from priming, or to break the siphon action once primed (Hardwick and Grant, 1997). These valves can be used as an external control refinement on the siphon by regulating the level at which the siphon primes. Several siphonweirs are often used together to allow for extra control, a so-called battery of siphons. Siphon batteries are usually arranged so that individual siphon-weirs come into action successively, and each additional siphon only primes when the discharge exceeds the capacity of those siphons already in use. The level of the entrance lip ( $Y_{s}$ in Figure 23.1) controls the level at which the siphon action is broken and overflow ceases, providing that the exit lip is submerged and no valves allow air to enter the siphon prior to this.

\subsection{Background Review}

Due to the large overflow capacity of the siphon-weir structures and their influence on the sewer system hydraulics, it is important that the model accurately represent the operation of these structures. It is difficult to compute the action of siphon-weirs accurately. In the past, it has been usual to use hydraulic model tests (Davis, 1952; Hardwick and Grant, 1997). As with the 
radial gate analysis discussed elsewhere in this book (James and Young, 2001a), most available theory for siphon-weirs uses only steady-state equations. Since one of the features of siphon-weirs is to maintain a fairly constant upstream water surface during siphon operation, steady-state assumptions may have some validity under normal operating conditions. The generalized orifice equation is used to compute the siphon-weir discharge:

where:

$$
Q=C_{s} A_{e}\left(2 g H_{s}\right)^{0.5}
$$

$$
\begin{aligned}
& C_{s}=\text { discharge coefficient of the siphon, } \\
& A_{e}=\text { exit area of siphon in } \mathrm{m}^{2}\left[\mathrm{ft}^{2}\right], \text { and } \\
& H_{s}=\text { siphon driving head in } \mathrm{m}[\mathrm{ft}] .
\end{aligned}
$$

The driving head on the siphon, Hs, is the difference in the water surface elevations (stage) across the siphon, as shown in Figure 23.1. Under siphon flow, the head $H_{s}$ is equal to the sum of the velocity head at the outlet, the friction head losses, and any other head losses (e.g. entrance losses, bends, etc.). The friction losses may be calculated by Forchheimer's formula:

where:

$$
H_{f}=\xi_{f} V_{e}{ }^{2 / 2} g
$$

Therefore:

$$
\begin{aligned}
\xi_{f} & =\text { friction coefficient, and } \\
V_{e} & =\text { velocity at the exit. }
\end{aligned}
$$

$$
H_{s}=\Sigma\left(\xi_{f} V_{e}^{2 / 2 g}\right)
$$

From (23.2) and (23.3), the siphon discharge coefficient or efficiency, $\mu$ is given as:

$$
\mu=1 /\left\{\Sigma\left(\xi_{f} V_{e}^{2} / 2 g\right)\right\}
$$

where $\mu=C_{s}$ (discharge coefficient).

The efficiency of the siphon depends on the form and length of the siphon and usually ranges between 0.6 and 0.8 , for hydraulically efficient shapes (Davis, 1952).

\subsubsection{Unsteady Flow}

The above equations apply only to steady-state conditions. As with the radial gate structures (James and Young, 2001a), the approach adopted here for the siphon-weir code has been to apply these steady-state equations within each time-step in the routing model. 


\subsection{New Coding for Siphon-Weirs}

Siphon-weirs are handled in the same manner as radial gates, and other diversion structures, in RGEXTRAN (James and Young, 2001a). Siphon-weirs are similar in layout to weir diversions, and operate as a weir until primed. Once primed, the siphon-weir behaves in a manner similar to the dynamic head pumps simulated in EXTRAN, where the discharge is determined by the dynamic head across the structure.

From Figure 23.1, it is apparent that external controls on the siphon (e.g., air valves) can be varied by use of the variables $Y_{1}$ and $Y_{s}: Y_{1}$ defines the level at which the siphon primes, and $Y_{s}$ the level at which the siphon action is broken. It is possible that an overflow structure may consist of a battery of siphons. Our new code for siphon-weirs, which has been inserted into RGEXTRAN, accounts for this situation and allows the use of multiple siphons at a single diversion node. This situation is analogous to a pump station that comprises several pumps of different capacities connected in parallel. Combining individual siphons into such a battery avoids coding the system as a series of very short pipe lengths, which may cause numerical instabilities in the model. The program prints an echo of the siphon-weir data and checks the input for errors, printing appropriate warning messages if necessary. The siphon-weir code is suitable for both metric and U.S. customary units, but all verification tests were done using U.S. customary units.

\subsubsection{Logical Structure of Siphon-Weir Computations}

The logic structure of these computations is given in Figure 23.2. As with the radial gate computations, the siphon weir computations in RGEXTRAN are based on known values of head at the upstream and downstream nodes. The discharge computations are controlled by the water level at the upstream junction. Again, this is analogous to the pump calculations in EXTRAN, where the pump rate is controlled by the water level in the wet well. Each siphon in the battery is treated individually, and the results are summed to give the total "link" discharge. If the computed water level at the upstream node is less than the siphon crest, then there is no flow over the siphon weirs. If the water level is between the crest and the user-defined priming level, the discharge is computed as weir flow. Once the water level exceeds the priming level, the discharge is computed as siphon discharge using Equation 23.1. Siphon discharge then continues until the water level drops below $Y_{s}$, and the siphon action is broken. Thus, it is possible in the case of multiple siphons in a battery that, during a time-step, one siphon may be primed while another is operating as a weir, and a third may have zero discharge. This is representative of a real 
situation, where the siphons in a battery would be staged so that the siphons come into operation successively, and only as the additional overflow capacity is required.

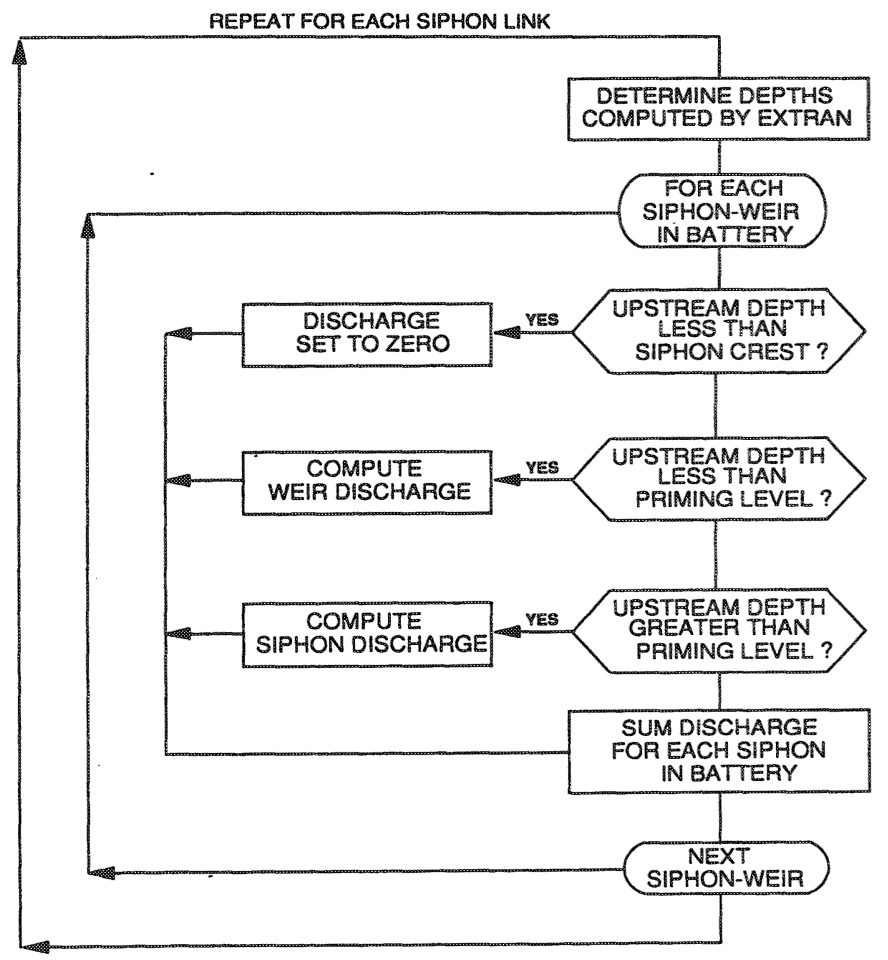

Figure 23.2 Siphon weir schematic.

\subsubsection{Code Verification}

The new siphon-weir code was verified using extensive test runs under a variety of different flow conditions. Results of these verification tests showed that the new code successfully simulates the theoretical operation of these structures. Figure 23.3 shows the results of an example test run using two siphons in a battery, with a simple hydrograph as input. Use of this simplified hydrograph allows steady-state conditions to be realized and the model results can easily be checked against the theory. Both the flow and depth plots in Figures 23.3 clearly show the operation of each individual siphon-weir, and it can be seen that the second siphon only comes into operation when the capacity of the first siphon is exceeded, as required by the theory. 

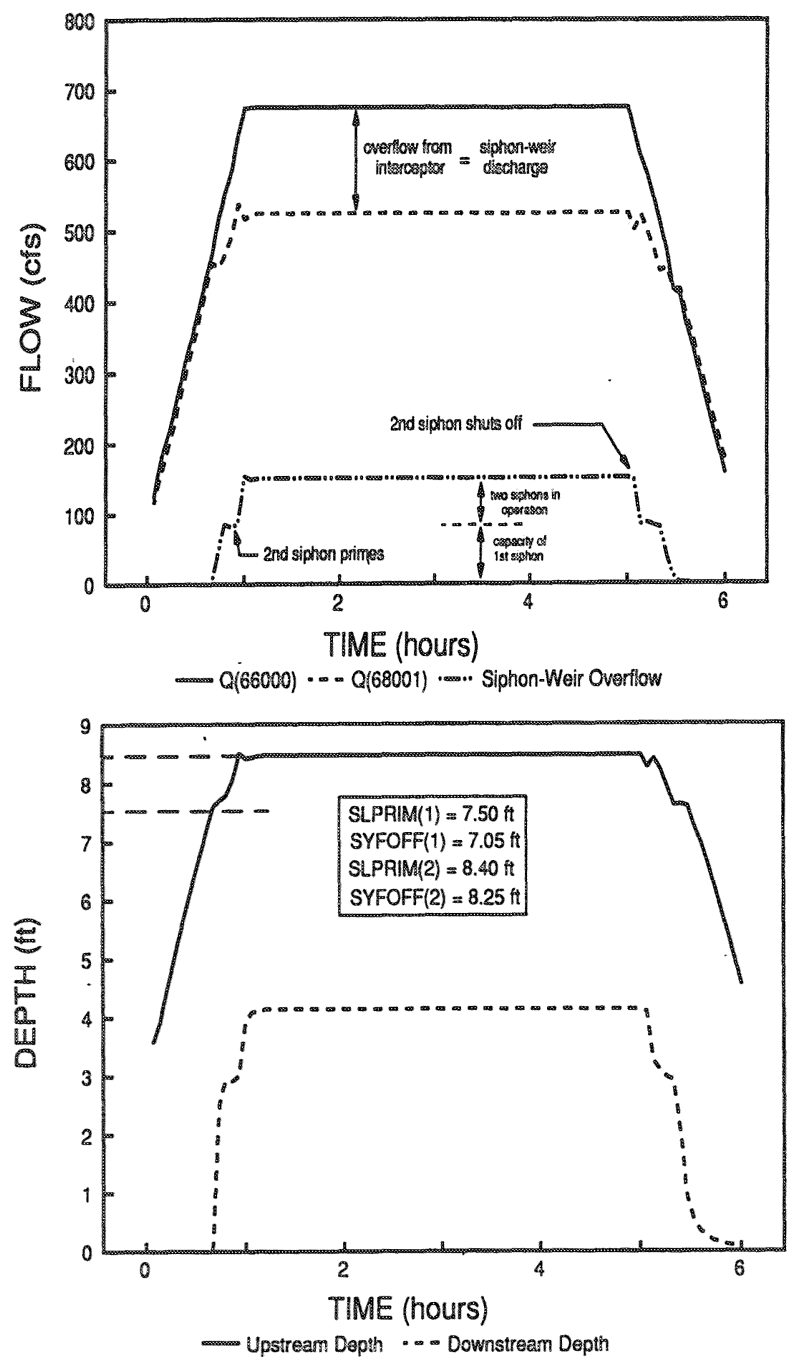

Figures 23.3 Computed hydrographs, flow and depth.

\subsubsection{Stability}

The siphon-weir computations were found to be stable under most conditions. This is partly due to the fact that, once primed, the discharge of these siphons varies little with changes in the upstream water levels. However, instabilities may be encountered when the siphon primes or shuts off. This situation is similar to a sudden pump start-up or shut-down. However, these instabilities are very short lived (a few time-steps), and often reflect hydraulic conditions occurring in the prototype. 
Care should be taken in specifying the variables $Y_{I}$ and $Y_{s}$. Due to the large capacity of these structures once primed, it is possible that the siphons may artificially "hunt" in the model. Thus, the sudden computed outflow due to the siphon priming may cause a lowering of the computed upstream water levels, which in turn causes the siphon action to be broken. The resulting increase in the upstream flow then causes the siphons to prime and the cycle is repeated. These artificial conditions also do not last for long periods, but the user should attempt to avoid them.

The effect of $Y_{I}$ and $Y_{s}$ on the siphon-weir computations is shown in Figure 23.4. It is evident from this figure that both these variables have a significant effect on the computed results, and should be accurately identified. The level at which the siphon action is broken, $Y_{s}$, has little effect on the peak siphon-weir discharge, but has a significant effect on the total overflow volume. As $Y_{s}$ moves closer to the level of the siphon-weir crest $Y_{c}$, the siphon action is broken sooner (i.e. at higher heads in the interceptor) as water levels in the interceptor begin to fall. Thus, the overflow event duration is shorter, and consequently the overflow volume is less.
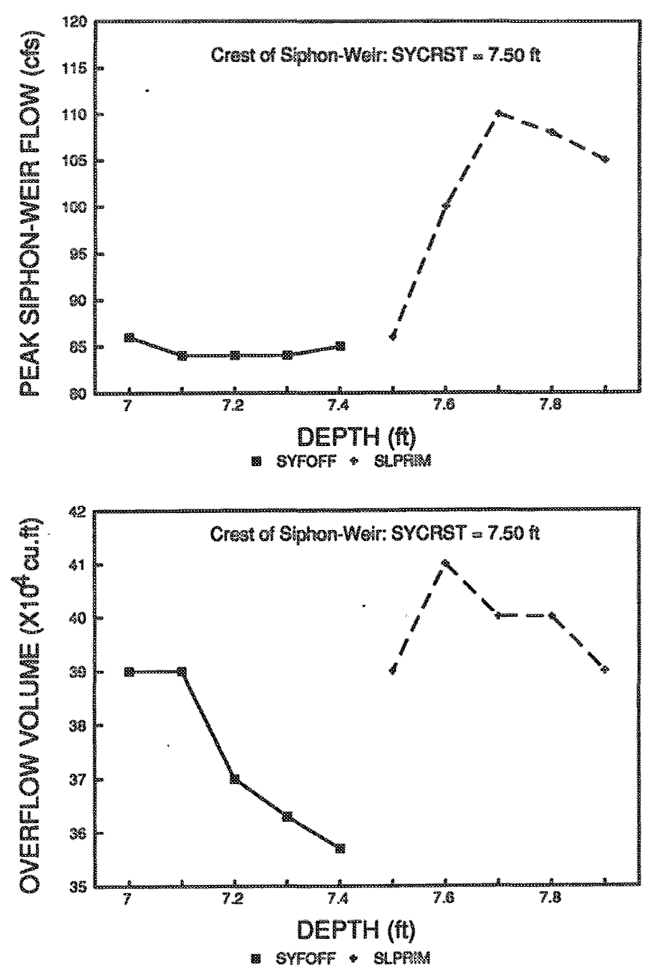

Figure 23.4 Rating curves. 
The influence of $Y_{1}$ on the siphon-weir computations is explained as follows. At low values of $Y_{l}$, the siphon-weir primes at lower depths in the interceptor. During siphon operation this upstream head in the interceptor remains fairly constant and the peak flow is reduced as a result of the lower driving head across the siphon. At higher values of $Y_{1}$, for the same flow in the interceptor, the siphon action begins at a higher upstream head. The driving head across the siphon is greater and the peak flow is increased. However, as $Y_{1}$ increases beyond a certain point, the peak flow is reduced as the higher upstream heads allow more flow to be conveyed in the interceptor. Since the overflow volume is dependent on both the peak flow and the overflow duration, the total volume initially increases as the peak flow increases. But as the peak flow and overflow duration decrease as a result of further increasing $Y_{l}$, and the flows in the interceptor are increased, the total overflow volume is also decreased.
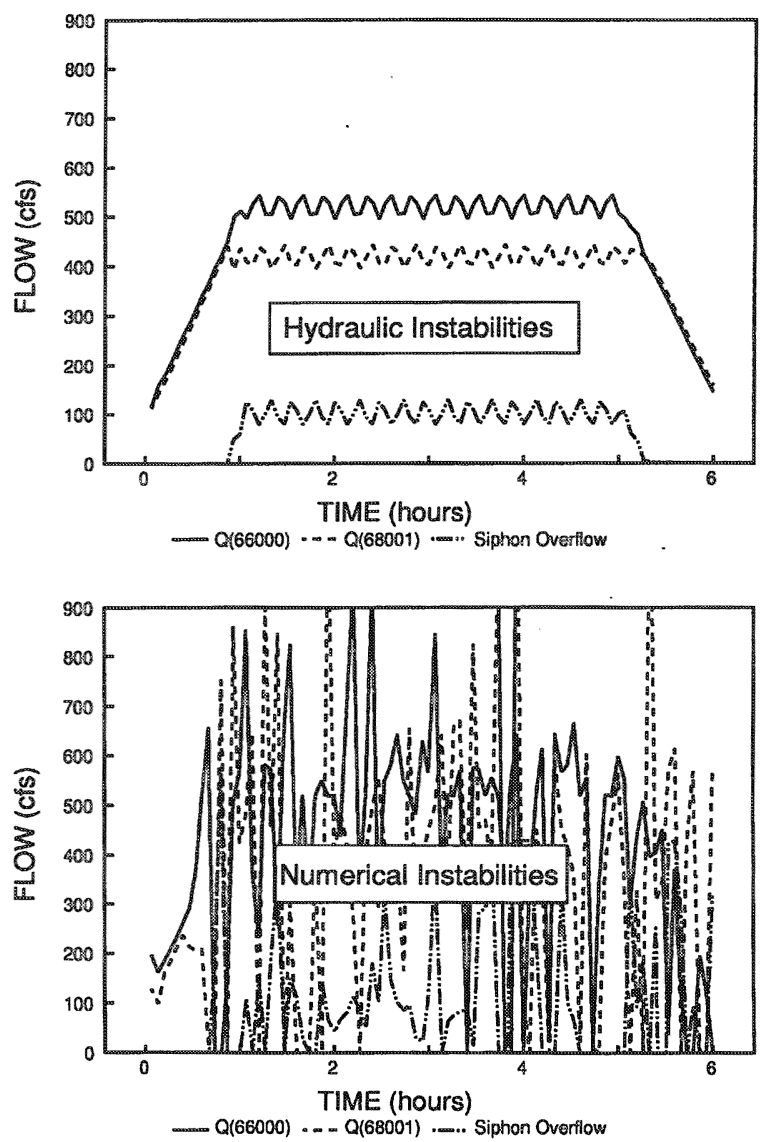

Figure 23.5 Computed instabilities. 
Figure 23.5 shows the difference between these hydraulic instabilities, and numerical instabilities in the model. The first plot shows the effect of hydraulic instabilities on the model results, and was generated using values for $Y_{1}$ and $Y_{s}$ which were very close to the crest level $Y_{c}$, causing artificial hunting in the model. The second plot was generated using a larger computational time step, which caused the numerical solution scheme to go unstable.

\subsubsection{Model Calibration}

The discharge coefficient of the siphon-weir, $C_{s}$, may be used in the model calibration procedure to match computed overflows to measured data. The effect of $C_{s}$ is evident from Equation 23.1 and is illustrated graphically in Figure 23.6.
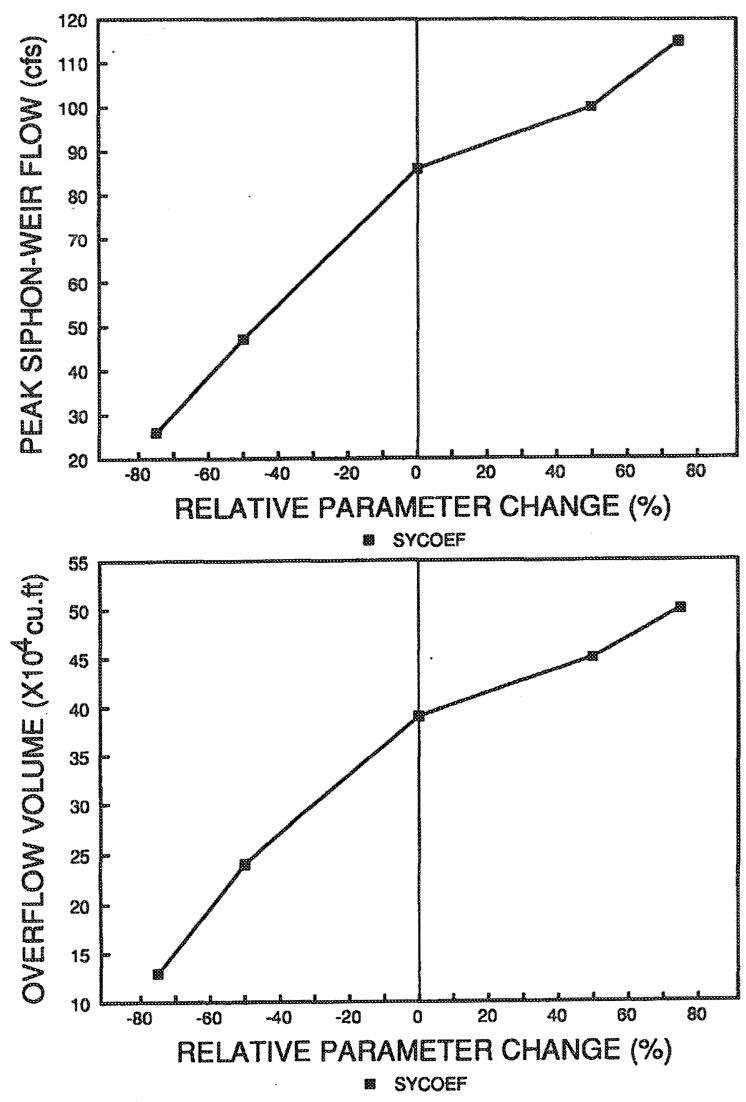

Figure 23.6 Siphon weir code calibration. 


\subsubsection{Model application}

For better calibration, but also to check performance and to improve the venting system that controls the sewer hydraulic grade lines at which the siphons either prime or shut off, a physical scale model was constructed of the siphon-weir. The physical model study confirmed that the vent systems can provide a finer level of control of the discharge (in other words, by having different siphon barrels prime and shut of at various levels). In this way CSOs could be reduced while still maintaining safe hydraulic grade lines in the interceptor system. RGEXTRAN was written with the ability to model these on and off controls and generally worked well, excepting for the finite difference model, when there is a tendency to hunt in alternate time steps (similar to real beahviour). When applied to the combined sewer system in Vancouver, British Columbia, results demonstrated that the new program accurately represents the operation and hydraulics of the dynamic radial gates and siphon-weirs found in the system (James and Young, 2001b).

\subsection{Conclusions}

New code has been developed for simulating the hydraulics of complex combined sewer systems with self-priming siphon-weirs. The new code was inserted into program RGEXTRAN, which combines the dynamic wave routing SWMM4 EXTRAN model with new source code developed for siphonweirs (and radial gates). The new code accounts for the hydraulic operation of siphon-weirs, and provision is made for simulating external controls on the siphons. The siphon-weir code has also been verified under a wide range of flow and operating conditions. Equations used are derived for steady-state conditions. Continuity is maintained at the siphon-weir locations at all times, except under unstable conditions.

\section{Acknowledgments}

Financial support for this project was provided by the Greater Vancouver Regional District, Computational Hydraulics International, the Natural Science and Engineering Research Council of Canada, and the University of Guelph, through grants to Bill. RGEXTRAN was developed by Brett as part of his MSc (Young, 1991), under Bill's "advisement". Bill abstracted this chapter from Brett's excellent dissertation 


\section{References}

Davis, V.C. 1952. Handbook of Applied Hydraulics (Second Edition). McGraw-Hill Book Company: New York. p. 253-288,1094-1119.

Huber W.C. and R.E. Dickinson. 1988. Storm Water Management Model User's Manual, Version 4. Environmental Protection Agency: Athens, Georgia. p. 136139.

Hardwick, J.D., and Grant, D.J. 1997. An adjustable air-regulated siphon spillway. Proc. Instn. Civ. Engrs. Wat. Marit. And Energy, 124:95-103. June 1997.

James, W. and B.C. Young. 2001a. "An Approach to Modeling Real-Time Control of Dynamic and Static Radial and Sluice Gates within EXTRAN." Journal of Water Management Modeling R207-22. doi: 10.14796/JWMM.R207-22.

James, W. and B.C. Young. 2001b. "Dynamic Modeling of Real-Time Control of Combined Sewer Systems with Radial Gates and Siphon Weirs." Journal of Water Management Modeling R207-24. doi: 10.14796/JWMM.R207-24.

Roesner, L.A., J.A. Aldrich, and R.E. Dickinson. 1989. Storm Water Management Model User's Manual Version 4: EXTRAN Addendum. Environmental Protection Agency (EPA): Athens, Georgia.

Schoklitsch, A. 1937. Hydraulic Structures. The American Society of Mechanical Engineers: New York. p. 574-582.

Vancouver City Engineering Department. 1985. Combined Sewer Overflow Abatement Study -Technical Report. Vancouver, B.C. p. 45-59.

Young, B. C. 1991. Dynamic modelling of combined sewer systems with radial gates and siphon weirs. MSc dissertation. Univ. Of Guelph, 1991. ca $120 \mathrm{pp}$ excl. appendices on disk. 
